MUZIKOLOŠKI ZBORNIK - MUSICOLOGICAL ANNUAL IX, LJUBLJANA 1973

UDK 786.2 Kogoj : 781.43

\title{
MELODIKA V KLAVIRSKIH SKLADBAH MARIJA KOGOJA
}

Ivan Kle menčič (Ljubljana)

Če primerjamo Kogojevo pozornost vertikalni in horizontalni gradnji v kompozicijskem stavku, ugotavljamo specifičen, a enoten pristop za domala vsa ustvarjalna obdobja. V tem pogledu je skladatelj nadaljevalec tradicije homofonskega načina glasbenega mišljenja, ki pa samo ni bilo zadostno in je $\mathrm{z}$ uvajanjem polifonije $\mathrm{v}$ obliki svobodnih glasov to homofonsko osnovo vsebinsko psihološko nadrobneje določilo. Kompozicijsko gre za nasledstvo tako imenovanega romantičnega kontrapunkta, ki je nastal $\mathrm{z}$ uvajanjem protimelodije nasproti temeljni melodiji in se je ob dodajanju novih sočasnih melodičnih linij še močno kompliciral, vključno do atonalnosti. To nam dokazuje razvojna pot od Schumanna in Chopina, prek Čajkovskega do Francka in Regerja, Wagnerja vse do Mahlerja, Schrekerja in Schönberga. Primerjava pokaže, da se je Kogoj povsem razvidno ujel $\mathrm{z}$ omenjenim razvojem na stopnji, $\mathrm{v}$ kateri je prišlo do potrebe po stopnjevanju izraza; od tod pojav polnjenja glasov in $\mathrm{s}$ tem določena hipertrofija in preobloženost kompozicijskega stavka, ki pa jo je skladatelj deloma tudi presegel.

Za klavirska dela je razvojno zanimivo, da izhaja Kogoj še iz razmeroma čiste monodične zasnove $\mathrm{z}$ melodijo in akordično spremljavo, obenem ko so nastavki polifonske obdelave $\mathrm{v}$ smislu orgelskega in zborovskega stavka ter diferenciranje akordovih tonov $\mathrm{v}$ glasove ter protimelodične postope, že prisotni. To velja zlasti za klavirskega prvenca, "Elegijo«, pa tudi za začetek "Piana«, mestoma še $s$ povsem naglašeno akordično zasnovo. Prav te značilnosti navajajo na sklepanje, da je mladi Kogoj v resnici izhajal iz homofonije, a da je že tudi težil $\mathrm{k}$ novemu izraznemu načinu, $\mathrm{k}$ preseganju gole homofonske kompozicijske metode. Obenem s samim procesom zorenja je to najbolje potrdil študij kontrapunkta na dunajski glasbeni akademiji, ki ga imamo lahko že po izbiri za značilnega. Kot posledica te skladateljeve težnje in razvijanja kontrapunktičnega mišljenja se novo hotenje zdaj povsem določno oblikuje. V razvojnem procesu pomeni obrat, ki ga odražajo že takrat nastale fuge, 
saj jih kljub klasični ekspoziciji označuje $\mathrm{v}$ izpeljavah in medigrah povečana zvočnost $s$ povsem svobodno širjenim tonskim obsegom $\mathrm{z}$ občasnim uvajanjem novih glasov.

Tako se torej kompozicijski stavek občutno okrepi in zgosti $\mathrm{z}$ razvejanostjo posameznih glasov, se kmalu nekoliko izčisti, in takšnega zadrži Kogoj z nekaterimi modifikacijami kot novi polimelodični slog še ves čas pozneje. Da ne gre zgolj za pogojenost v polifoniji, marveč za nov pristop, dokazujejo poslej še zlasti homofonsko zasnovane kompozicije. Na primer v »Sarabandi« se skladatelj posluži zelo značilnega izločanja posameznih akordičnih glasov od basa do soprana in jim $\mathrm{z}$ opisovanjem posameznih hormonskih tonov, prehodov in $\mathrm{s}$ pomočjo kromatičnih prehodov $\mathrm{za}$ medsebojno vezavo akordov vtisne samostojnejše življenje.

1. „Più grave« (»Sarabanda«), t. 1-3.

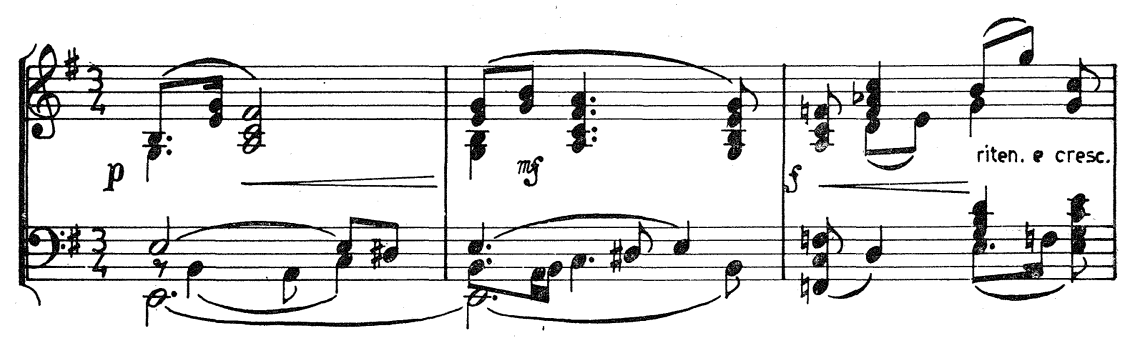

Tako je pozornost kljub navpičnemu poteku namenjena do določene mere že tudi vodoravni črti, čeravno o pravi linearni zasnovi ne moremo govoriti. Še na poseben način je razvidna razlika med novim in starim načinom iz prve skladbe "Piana«. S primerjavo čistejšega homofonskega in polimelodičnega koncepta ugotavljamo, da je ob ohranjeni starejši zasnovi - od takta dvaindvajset do ponovitve in od sedeminpetdesetega takta do konca - prišlo $\mathrm{v}$ samem začetku skladbe in $\mathrm{v}$ ponovitvi do poznejših posegov $\mathrm{z}$ vnašanjem dodatnih glasov, ki naj bi dopolnili in zgostili prvotni preprostejši skelet. O tem še posebej priča basovski del prvega in drugega takta kompozicije kot melodično opisovanje akordov h-mola, e-mola in zatem E-dura in g-mola, ali nadaljevanje po ponovitvi v osmem taktu, tudi z vnašanjem novih kompliciranejših poliritmičnih obrazcev. Opraviti imamo skratka $\mathrm{z}$ dvema, po zasnovi različnima kompozicijskima plastema in med drugim prav po tem in po gradnji akordov lahko sklepamo o nastanku dela še pred dunajskim študijem in o dopolnitvah ob njem ali po njem.

Kajpada je razumljivo, da pride do skrajne izrabe novega kompozicijskega načina posebno $\mathrm{v}$ bolj polifonsko grajenih kompozicijah, čeprav te niso zastopane $\mathrm{v}$ tolikšni meri in so tudi po nastanku omejene v zgodnejši čas. Ni naključno, da štejemo $\mathbf{k}$ izrazitim primerom tega zgodnjega a ekstremnega polimelodičnega sloga prav »Prélude«. Tu se oblikuje v melodičnem pogledu, s kombinacijo po- 
sameznih glasov z izredno gosto razporeditvijo tonov, nekakšna mreža, napolnjenost kompozicijskega stavka v vertikalni in horizontalni smeri,

2. »Prélude«, t. 20.

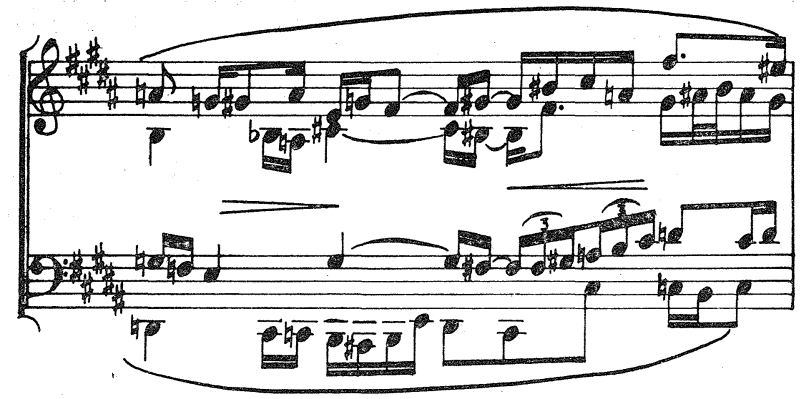

kakršne skladatelj pozneje več ne doseže, prej pa le v fugah. Kot kažeta zadnji dve skladbi iz "Piana«, nagiba Kogoj iz specifičnih izrazno vsebinskih razlogov v ljubljanskem obdobju do "črnih mask" $\mathrm{k}$ bližnji homofonski zasnovi in tako opušča ta prijem, čeprav zadrži - mimo nekaj redkejših akordičnih mest - temeljni polimelodični zasnutek. Po tem drugem izhodišču in še dosledneje grajena je "Skica", opirajoča se na model »Sarabande«, s poudarkom na akordu, a s še bolj razvejanimi posameznimi glasovi.

In kar je s slogovnega stališča prav tako zanimivo, podobno ali vsaj večidel podobno zasnovo zadržijo kljub širšemu in raznovrstnejšemu oblikovalnemu pristopu tudi »Malenkosti«. S tem se torej skladatelj ni odpovedal pridobitvam svojega zrelega obdobja, spremenil je le način obdelave tako, da je nekdaj bujno in včasih še komaj kontrolirano polimelodično prepletenost nadomestil $\mathrm{z}$ bolj linearno pojmovano, v glasovih čisteje, bolj asketsko izpeljano melodiko bodisi kromatičnega ali sem in tja diatoničnega tipa. Evolucijska pot $\mathrm{k}$ izčiščenju kompozicijskega stavka $\mathrm{v}$ smeri linearizma in postopnem preseganju nekdanje polimelodike,

3. »Malenkosti«, XI, t. 1-3.

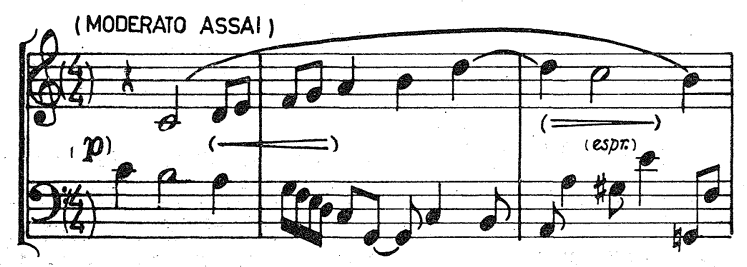

ki jo $\mathrm{v}$ še doslednejše izpeljani obliki zasledimo $\mathrm{v}$ zadnjih samospevih, pa kljub temu ni $\mathrm{v}$ celoti zaključena. To pomeni, da $\mathrm{v}$ še 
nedokončanem postopku preoblikovanja - in ne opuščanja - načela o kompozicijskem izražanju $\mathrm{v}$ večglasju, s pomočjo več glasov hkrati, začne bolj vertikalni način gledanja $\mathrm{v}$ zadnjem obdobju nadomeščati horizontalnejši vidik, čeprav združujeta eden in drugi sestavine nasprotnega, homofonskega in polifonskega.

Poudariti je treba, da je ta ugotovitev kajpada razumljiva s stališča odklonov in izjem $\mathrm{v}$ smeri linearnejše ali akordične obdelave kompozicijskega stavka prej in pozneje, če se posebej ne oziramo na inačice zaradi vsakokratnih vsebinskih zahtev kompozicij, ${ }^{1}$ medtem ko ostaja osnovna usmeritev nespremenjena.

Podobno kot polimelodiko, obravnava Kogoj na specifičen način tudi sámo melodiko. $\mathrm{Z}$ ene strani si melodije ne zamišlja kot tonsko kontinuirane, širše razpredene tvorbe, saj jo ponavadi razbija na drobne enote in iz njih sestavlja pomensko enovit kompozicijski tok. $\mathrm{Z}$ druge strani poudarja največkrat eno takšno melodično linijo kot nosilko izraza, ki jo postavlja v različne glasove - najpogosteje v zgornjega - in jo druge spremljajo ali melodično dopolnjujejo. Kljub stičnim točkam $\mathrm{s}$ tradicijo ima $\mathrm{v}$ tem pogledu skladateljeva usmerjenost $\mathrm{v}$ atomizacijo pečat naprednega in izvirnega prepričanja, ki je tudi teoretično razjasnjeno. Skladatelj pravi: "Niti napev niti têma nista za glasbo neizogibno potrebna, dasi je zbor kritikov zagnal oglušno vpitje, da se glasbena umetnina sodi po tem, ali ima melodijo ali ne. Glasba brez napeva je bila že davno. Podlaga glasbenega snovanja more biti v tem primeru glasbeni zasnov ( $\mathrm{tj}$. motiv). More pa biti tudi kaj drugega. če je glasba melodična, če zveni blagodejno, če skladnost glask tako vabljivo kliče človeka, še nikakor ne pomeni, da ima melodijo. ${ }^{2}$ Zavračanje klasičnih načel opira Kogoj tu na zaključenost in urejenost romantične melodije, ki, sledeč lastnim oblikovno estetskim zakonitostim, ne more ustrezno slediti in se prilagajati hitro spremenljivemu, raznovrstnemu psihičnemu dogajanju ter se sproti odzivati njegovim vzgibom. Še neprikladnejša mu je oblika tematične gradnje, in sicer zaradi formalne organiziranosti in vklenjenosti, s tem pa zavisnosti v izraznem in oblikovnem pogledu. Zato se $\mathrm{v}$ obeh primerih odloča za široko uporabnost motiva in njegovo obdelavo, torej za melodično sredstvo, ki lahko zagotovi vsebinsko oblikovno zaokroženost kompozicije in postane namesto klasične melodije osnovna melodična in oblikovna celica kompozicijskega stavka. Ko omenja druge možnosti melodične gradnje, tudi na podlagi klavirskega kompozicijskega stavka, domnevamo, da misli z njimi na oblikovalne načine neformalne narave, strnjene pod

1 Prim. »Allegretto«, odstavek »Con fuoco«, s kratko obdelavo kanona, ali »Skico« t. 4-6, ki dopušča več linearnosti, če posebej ne omenjamo fug. Akordična mesta so izrazita v »Skici« od t. 21 naprej ali v "Andantino sostenuto", t. 53-54, značilno s tendenco formiranja glasov, ali t.64. Vendar jih zasledimo prav tako poudarjene v "Chopiniani« ali v »Malenkostih", npr. XVI ali III, t. $1-2$ in 24, v XXII itd. 112 .

2 Kogoj M., O umetnosti, posebno glasbeni, Dom in svet XXXII/1919, 
pojem glasbenega domisleka. Zlasti $\mathrm{v}$ polimelodičnem tkivu rabi motivu podoben, a svobodneje oblikovan in formalno navezan melodični utrinek, ki nastopa bodisi enkratno ali se pozneje razvija le, kakor ga narekuje skladateljeva invencija. Takšen je lahko nosilec atematične zasnove ali nenehne variacije Schönbergovega tipa, ali pa - kot pri Kogoju najpogosteje - poleg motivov sestavina vsega drugega melodičnega gradiva $\mathrm{v}$ skladbi. Vendar je značilno, da se vsi ti načini, ne glede na še formalni ali docela svobodni vidik, podrejajo Kogojevi zahtevi po estetski in vsebinski skladnosti v smislu spevnosti, torej načelu, ki dobiva po izročilu 19. stoletja novo, poglobljeno vsebino.

Če si hočemo osvetliti to zadnjo karakteristiko, potem ne moremo že mimo klavirskih fug. Čeprav so kot edine klavirske kompozicije podvržene strogi tematični obdelavi, je prav element spevnosti tisti,' ki jih loči od baročnega vzora. Specifična zanje je ponekod celo določena sorodnost $\mathrm{z}$ duhom in lirizmi chopinovske melodike, še zlasti pri f-molovi fugi kot celoti in posebej njeni prozornejši ekspoziciji, pa tudi v G-durovi. Poslednja vsebuje vrh tega značilne melodične obrate, kakor jih npr. prinaša polifonsko gradivo ob ekspoziciji druge teme. Sama tema, ki nastopi v basu na drugo polovico druge dobe, je glede tega nevtralna, toda njena kontrapunktična interpretacija $\mathrm{v}$ tenorju ji daje $\mathrm{z}$ melizmom izrazit chopinovski značaj. Srečujemo se torej s posebno, a nedvoumno in na splošno razpoznavno obliko melodičnega izražanja, ki je obenem zgovoren dokaz, da je bil skladateljev namen $\mathrm{v}$ danih okvirih $\mathrm{z}$ umetniškimi sredstvi obvladati zgolj tehnični, šolski značaj fuge in ji vtisniti novo vsebino in izraz.

Sicer se v smislu preseganja tematike in izdelane melodije uveljavlja načelo podajanja melodičnega gradiva kot izrazno spevnega elementa s pomočjo motivične gradnje. Kako intuitivno si ga je Kogoj prisvojil, na neposreden način izpričuje prvenec »Elegija«. Dovolj značilno in nenaključno je že dejstvo, da je skladatelj na začetku ustvarjanja zavrgel možnost izdelave zaokrožene melodije, samostojne ali v okviru osemtaktne periode, in se oprl na zaključenost enotaktnega motiva.

4. "Elegija«, t. 1-2.

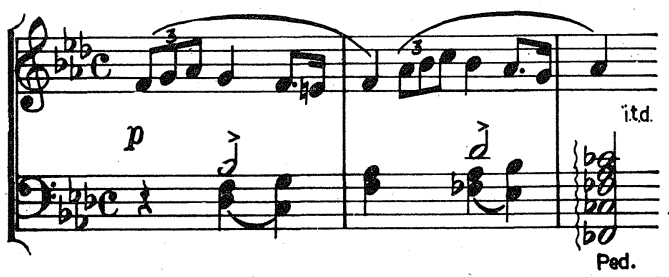

Navkljub temu, da ga je $\mathrm{z}$ manjšimi modifikacijami tonskega poteka delno še postavil $\mathrm{v}$ šesttaktje, $\mathrm{mu}$ je dal ritmično melodično in tudi harmonsko pomen samostojne, sebi zadostne vsebinske in 
melodične enote. Kot je bil $\mathrm{v}$ tem pogledu premočrten, pa se po drugi strani $z$ majhno izkušenostjo še ni mogel izogniti skrajnosti ali vsaj nevarnosti, ki jo prinese izključenost, samozadostnost motiva ( $\mathrm{z}$ vklenjenostjo, začetkom in sklepom na toniki) ter njegovo ponavljanje brez zaznavnejše pomenske izpeljave. Zato je kot neizogibna posledica nastopila vsebinska neizčrpanost in $\mathrm{z}$ njo določene praznine, ki so se $\mathrm{v}$ najbolj kritični luči zgostile ob sklepu skladbe. Tu je namreč skladatelj s poslednjim citiranjem motiva skušal sumirati dotedanji potek kompozicije, kar je - še celo patetično podkrepljeno $\mathrm{z}$ deljeno dinamiko motiva (fff - ppp), privedlo le do deklarativnega sklepa. Sklicevanje na domnevno prejšnjo polnost in pomembnost doživetja ob zaključnem obratu se je izkazalo za neutemeljeno, izpeljava začetne ideje $\mathrm{z}$ že tako kratkosapnim melodičnim jedrom pa tokrat še za nedodelano in nedozorelo.

Obenem $\mathrm{s}$ to značilnostjo melodike $\mathrm{v}$ zgodnji fazi se ujema odnos do polimelodike; razvejanost glasov je prav pri »Elegiji« - kot je bilo ugotovljeno - skromnejša in neizrazita ter $\mathrm{z}$ nakazano samostojno izpeljavo s svoje strani pripomore $\mathrm{k}$ opisanemu učinku skladbe. Sklepamo lahko, tudi po pozneje popravljani skladbi »Andantino cantabile«, da je moral biti skladatelj soočen $\mathrm{z}$ ne nevažnim estetskim vprašanjem polnosti izraza, ki se je tu razodeval $\mathrm{v}$ določeni neintenzivnosti, praznosti mest povsod tam, kjer spremljajo melodijo čisti akordi. Problem preveč prozorne, poenostavljene kompozicijske gradnje je bil $\mathrm{v}$ bistvu problem psihološke narave, saj se je nanašal na kontinuteto in intenzivnost glasbenega doživljanja in podajanja. Toda rešitve Kogoj ni iskal v smeri lapidarnega izražanja po vzoru Webernove abstrakcije, marveč jo je našel svojemu načinu glasbenega mišljenja primerno $\mathrm{v}$ stopnjevanju izraza $\mathrm{z}$ razširitvijo ene melodije $\mathrm{v}$ več sočasnih, dopolnilnih. Če motrimo $\mathrm{s}$ teh vidikov razvoj Kogojeve klavirske kompozicije, moramo označiti "Elegijo" kot poskus, ki stoji na samem začetku formiranja skladateljevih kompozicijsko izraznih sredstev.

Tako je šele novo pridobljena tehnika izražanja $s$ pomočjo več glasov ob glavnem, $\mathrm{z}$ motivično izpeljavo, skladatelju omogočila vnašanje pomenskih odtenkov ter polnost $\mathrm{v}$ psihično nepretrganem, širokem izraznem toku. $\mathrm{Z}$ novimi možnostmi je Kogoj kmalu dosegel tudi skrajno nasprotje izhodišču, če sklepamo po preludiju v H-duru, obenem s to skrajnostjo pa tudi nov odnos do temeljne motivike zaradi oživljanja glasbenega domisleka. Tako se $\mathrm{v}$ imenovani skladbi začetna glasbena misel $\mathrm{v}$. sopranu, ki sestoji iz enotaktnega motiva $\mathrm{z}$ izrazitim vzponom in padcem melodije na izhodišče ter zaključno skupino v drugem taktu, pojavlja le nekajkrat $\mathrm{v}$ melodično variirani in $s$ tem zabrisani obliki. Tem razsežnejše pa je področje melodičnih domislekov, tudi kot bolj organiziranih jeder, ki se opirajo največ le na posamezne ritmične značilnosti začetne motivike, s čemer dosegajo presenetljivo sorodnost in povezanost $\mathrm{v}$ svobodnem, skladatelju najbolj ustreznem poteku. 
5. »Prélude«, t. 21-22.
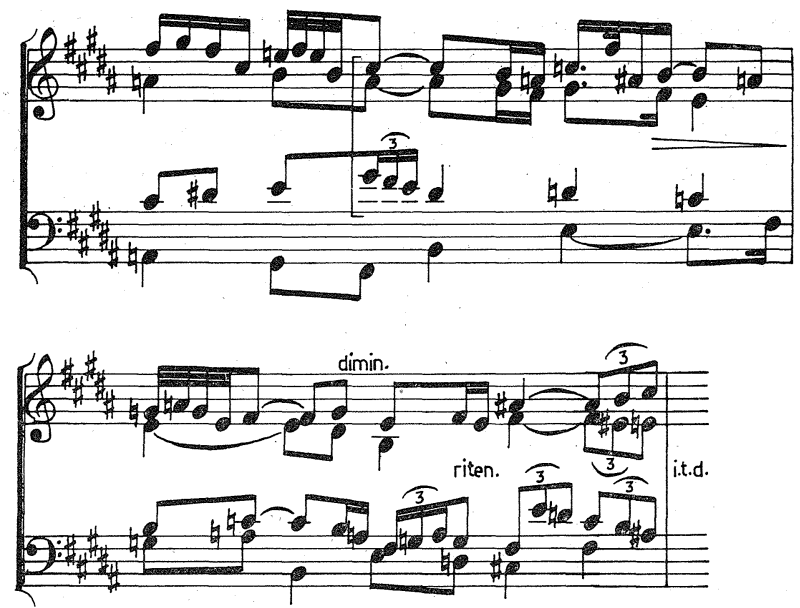

Tudi tu, če bi ritmična zgradba melodike dovoljevala še sklepanje o vzorih pri Bachu, je element spevnosti tisti, ki postavlja $s$ staro baročno obliko ostro ločnico. Trditi smemo celo, da je naslon na melodiko chopinovskega tipa $v$ »Preludiju« najbolj izrazit in ga je zlasti z uvodnim motivom mogoče šteti kot nekakšen »hommage« poljskemu skladatelju. Če Kogoj v naslovu tega posebej ne poudarja, ga najbrž zadržuje zasnova drugih kompozicijskih elementov, posebej v odnosu harmonija-polifonija, ki je v »Chopiniani« nedvomno monodično oz. zmernejše polimelodično dovolj značilna, medtem ko gre po občutenosti in toplini melodike prednost preludiju.

Po tipu uporabljene melodike prihaja razumljivo do različic, ki so zavisne od vsebinske zasnove in razvojnih značilnosti skladb. Ponekod, kot npr. v »Più grave«, je narava motiva - zaradi naslona na oblikovno gradnjo sarabande - evidentnejša, drugje, zlasti spočetka, je motivika zajeta v izrazitejše melodične linije, kar je poleg "Prélude " tudi značilnost prvega dela »Piana«, le da tudi tu naslon na formalno načelo periodiziranja še ni povsem opuščen. Zato se pri drugem načinu pogosteje srečujemo $\mathrm{z}$ osamosvajanjem določenih glasbenih domislekov, ki so motivično le še malo povezani z začetno, večkrat že po obsegu omejeno motivično celoto. Kot kaže primer iz "Allegretta«, se od začetne glasbene fraze razlikujejo po povsem drugačnem glasbenem izrazu, čeprav jih skladatelj lahko tudi iz delno prisotnih formalnih ozirov variirano navaja še pozneje, po citiranju drugega novega melodičnega gradiva. Posebnost melodike iz primera, ki označuje Kogoja tudi pozneje, je značilen združen, zelo intuitivno dobljen učinek posameznih melodičnih linij, tako temeljne, akordično izražene $\mathrm{v}$ sredini, kakor sopranske, ki daje sekvenci gibanje navzdol, ob prosto nastopajočem, neobhodnem basu zgolj na 
prvo dobo. ${ }^{3}$ Celota ne deluje s tem le melodično polno in nedeljivo, marveč tudi samostojno, kot sebi zadosten muzikalni domislek, zasnovan na motivični in ne tematični podlagi; čeprav povezanost $\mathrm{v}$ okviru desettaktja nasproti uvodnemu sedemtaktju tu še ni povsem zabrisana, stopa vklenjenost formalne narave zaradi vsebinsko melodičnega poudarka $\mathrm{v}$ ozadje.

6. »Allegretto«, t. 8-9.

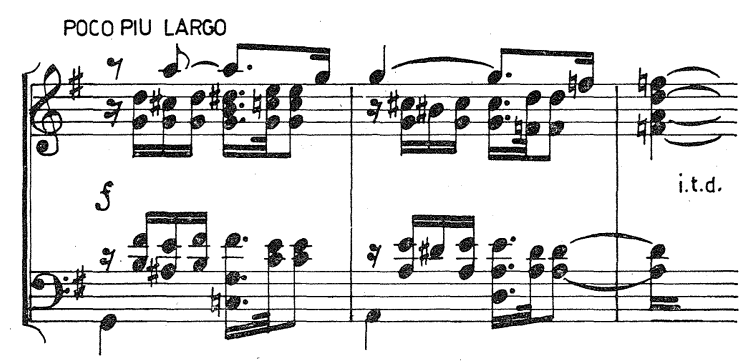

Nekoliko pozneje v ljubljanskem obdobju spevni značaj melodike prav tako ne izgine, čeprav je naslon na motiv izhodišče melodične gradnje. Le v "Più mosso" ima melodika - še posebej okvirnih odstavkov, bolj recitativični značaj, ali v "Skici« do desetega takta abstraktnejšega, dasi poudarjeno ekspresivnega, medtem ko je $\mathrm{v}$ "Dolce e tranquillo«, z dolgimi notnimi vrednostmi, blizu koralnemu melodičnemu tipu. Sicer prihaja tudi v zadnji skladbi »Piana«, na podlagi vsebinske in ne formalno motivične povezanosti, do primerov izrazite melodične gradnje. Polimelodična celota je že na začetku (t. 14-15) nedeljiva in povezana $\mathrm{z}$ isto glasbeno mislijo $\mathrm{v}$ tenorju, $\mathrm{v}$ večjih intervalnih postopih in manjših $\mathrm{v}$ sopranu. Njuno prepletanje daje občutek gibanja in prehitevanja, kar ustvarja glede na sam temeljni, prešerno radostni izraz glasbene misli celoti poseben značaj, ki dobi z melodičnim postopkom na koncu, od tona des ${ }^{2}$ do $\mathrm{es}^{2}$ in $\mathrm{z}$ uporabo celotonske lestvice, $\mathrm{v}$ resnici pečat pomenskega stopnjevanja. Tudi $\mathrm{v}$ »Skici« pride $\mathrm{z}$ desetim taktom do melodične sprostitve $\mathrm{z}$ obdelavo in ponavljanjem enega melodičnega domisleka, še v večji meri pa je spevnost melodike značilna za "Andantino sostenuto«.

Č si ogledamo kompozicijo nadrobneje, ji tega sicer ne omogoča enotaktni motiv na začetku, ki se v pettaktju zgolj s poltonskimi pomiki melodije drži tona $\mathrm{e}^{1}$, podobno kot Chopinov preludij v e-molu - le da pri Kogoju s polimelodično zasnovo ostalih glasov, marveč

${ }^{3}$ Gl. tudi izrazit primer ob koncu skladbe, t. 74-77, kjer se melodična postopa $\mathrm{v}$ altu in sopranu izmenjaje dopolnjujeta, sta torej vsebinsko zavisna, saj eden izhaja iz drugega; s tem sestavljata harmonično celoto, v kateri bi odsotnost enega izmed njiju bistveno osiromašila značaj in prepričljivost izraza. 
njen nadaljnji razvoj. Ob povezanosti melodičnega gradiva prihaja do izrazitih spevnih mest, kakor je naslednji domislek

7. »Andantino sostenuto«, t. 13-14.

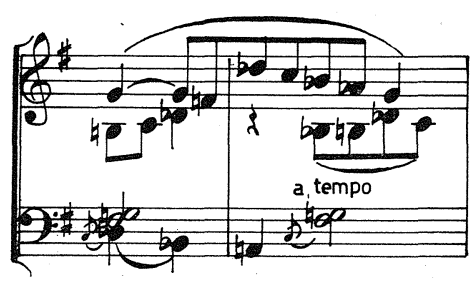

chopinovskega melanholičnega značaja v sopranu, ki spremlja na koncu melodije $\mathrm{v}$ altu po začetni spremljavi posnete (t.2, alt) štiri kromatične tone, $\mathrm{v}$ nadaljevanju še imitacijsko obdelane. Tako pripravi skladatelj nov odstavek »espressivo" s preprostimi kvartnimi postopi melodije navzgor in spevno bogato opisanim zaključkom te glasbene misli. Že v tem primeru gre za uvajanje novega melodičnega materiala po mozaičnem načelu gradnje kompozicijskega stavka, značilnega za »Črne maske«; naslednji zgled

8. »Andantino sostenuto«, t. 41-42.

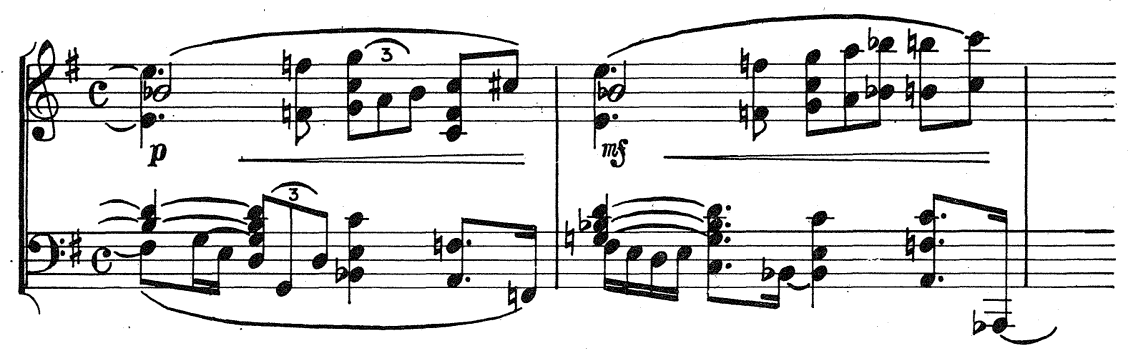

$\mathrm{z}$ nakazano ponovitvijo enotaktnega melodičnega vzorca takoj v naslednjem taktu, pa se kot anticipacija z njimi že povsem indentificira. Izolirano vzeto gre za spevno, docela novoromantično občuteno melodično gibanje, kakršnih zasledimo v skladbi še nekaj in ki lahko nastopijo, kot dokazuje izpeljava viška v taktih 65-66, v oblikovnem smislu povsem nevezano, dasi tu še motivično sorodno, toda kot rezultat skladateljevega intuitivnega vživljanja v vsebinski potek kompozicije. Na tej podlagi, $\mathrm{z}$ neposrednim vpeljavanjem nove melodike in $\mathrm{z}$ izpeljavo starih melodičnih domislekov ter njihovo medsebojno sorodnostjo, ${ }^{4}$ dosega Kogoj estetsko raznolikost v enovitosti, nenehno

${ }^{4}$ Spremljevalna figura, ali bolje motiv $\mathrm{v}$ tenorju "Andantino sostenuto", t. 2, nastopa zrcalno inverzno v t. 7-8, sopran, v t. 13-16 že kot imitacija svobodneje oblikovanega štiritonskega zaporedja, dalje nekoliko modificirano kot spremljevalna figura $\mathrm{z}$ melodijo $\mathrm{v}$ basu akordov t. 43-46 in kot sama melodija v t. 44-46. V istem drugem taktu kompo- 
spremenljivost melodičnega toka $\mathrm{v}$ poenotenem in spevno zasnovanem kompozicijskem stavku.

To načelo melodične gradnje $\mathrm{z}$ motivi in glasbenimi domisleki obvelja tudi ves čas pozneje, le da je zdaj podrejeno drugačnim izrazno vsebinskim izhodiščem. Melodična tvorba je koncipirana $s$ poudarkom na linearnem poteku, ne da bi vsebovala $s$ tem - posebno ritmično - bistveno preglednejšo, urejenejšo shemo. Skladatelj zadrži tako del nekdanje nekontrolirane, nevezane oblikovanosti, deloma pa se prilagaja zahtevam novega, objektivnejšega izražanja. $\mathrm{V}$ tem pogledu samosvojo, specifično rešitev, presenetljivo zaradi opuščanja nekdanjega naziranja o avtonomnosti melodične linije, si pridobi s konstruiranjem določenih medsebojno zavisnih, sočasno nastopajočih melodičnih linij. Te postanejo $\mathrm{v}$ inačicah različnih protipostopov nepogrešljiva sestavina vodoravne gradnje po »Črnih maskah". V "Malenkostih" in "Chopiniani« je omenjeno melodično načelo konstruktivizma prevzeto najizdatneje, bodisi kot realizirano razmerje dveh, $\mathrm{tj}$. obeh glasov,

9. »Malenkosti«, I, t. 6.

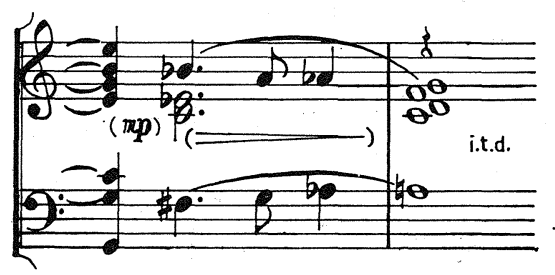

ki se $\mathrm{z}$ motivičnim gradivom pomikata kromatično navznoter, ali delno, kot kaže zgled $\mathrm{v}$ diskantu,

10. »Malenkosti«, I, t. 18.

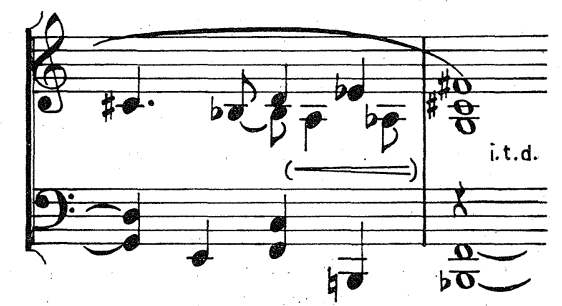

$\mathrm{s}$ širjenjem dveh glasov navzven, ki se jim (na zadnji dve dobi) pri-

zicije soroden, dasi ne identičen je motiv $\mathrm{v}$ altu, ki ga skladatelj preoblikuje in razvija $\mathrm{v}$ altu (t.10-12) in povzame akordično $\mathrm{v}$ diskantu (t. 12-13). Toda s poltonskimi premiki zelo blizu temu gradivu je sopranska melodija v začetnih tekstih skladbe, kar priča - $z$ vso nadaljno obdelavo skladbe - o enovitosti zasnove melodike $\mathrm{z}$ motivično gradnjo ali s sorodnostjo melodičnega gradiva. 
ključi v težnji navzven še bas. V linearnem smislu se lahko obravnava poslužuje tudi oblikovanja akordov,

11. »Malenkosti«, I, t. 10-11.

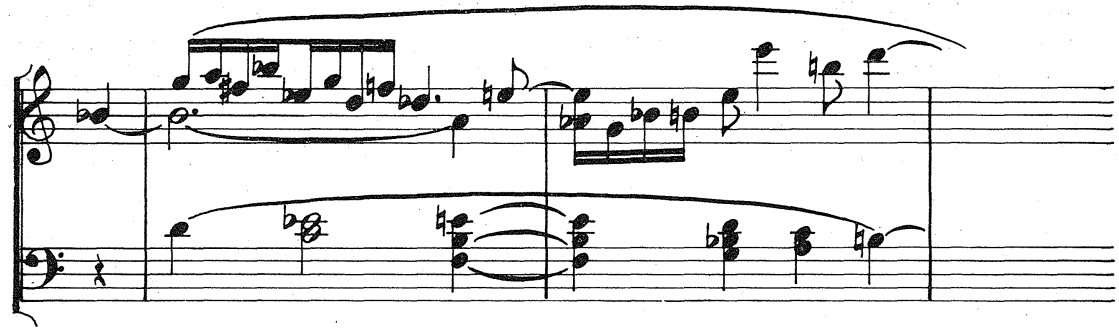

upoštevajoč, kot kaže zgled, od izhodišča do sklepa takšne tvorbe - $s$ posamičnim tonom, zavisnost $\mathrm{v}$ triglasju. Poleg oženja in širjenja delov polimelodične celote, $s$ katerimi je prepreden kompozicijski stavek v zadnjem obdobju, ${ }^{5}$ pride celo do popolne racionalne organizacije melodije.

12. "Malenkosti«, XVII, t. 25-27.

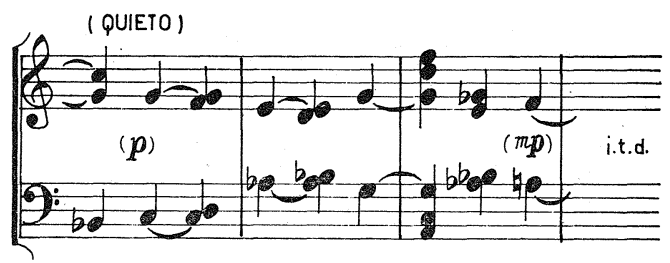

${ }^{5}$ Gl. še druge protipostope v "Malenkostih" II, t. $1-3$ v basu in t. 24 $\mathrm{v}$ diskantu, III, t. 7-8 v diskantu ali t. $33 \mathrm{v}$ basu, VI, t. $18-19 \mathrm{v}$ basu, VI, t. 18-19 v basu prvi takt navznoter, nato navzven, t. $21-27 \mathrm{v}$ diskantu akordični postopi $\mathrm{v}$ štiriglasju, sprva navznoter, nato navzven $\mathrm{z}$ reduciranjem do dvoglasja in po širjenju do enoglasja. Dvoglasne postope do enoglasja imata prav tako $\mathrm{v}$ diskantu sedma skladba, t. 19 in osma, t. 6 in t. 6-8, začenši $s$ triglasjem, ali t. 35-37 triglasje s postopi navzven do zaključnega petglasja. Več takih postopov najdemo tudi v deveti kompoziciji, že od začetnega širjenja (t.1 in 3) v diskantu, ali v vseh glasovih (t. 4-5) in nadaljnem poteku $\mathrm{v}$ diskantu (t.12), ali posebej $\mathrm{v}$ diskantu oženje od triglasja do enoglasja, obenem $z$ oženjem med basom in diskantom (t. 13) ter še pozneje $v$ diskantu (npr.t. 20), ali najprej širjenje v diskantu, zatem zapiranje spremljave v basu in spet diskantu (t. 23-25). Poleg desete skladbe (t. 4-5 in 15-16) in njenega konca (t. 21-23), ki vodi $\mathrm{v}$ diskantu navzven od enoglasja prek dvoglasja do triglasja ter se nato še oži in razširi do štiriglasnega akorda, se $\mathrm{z}$ novim prijemom srečujemo še večkrat (XI, t. $1-2$, XIII, t. 12-13 v basu, XV, t. 7 v diskantu), npr. izrazito kromatično v sedemnajsti skladbi med takti 4-7, sprva s širjenjem obeh zunanjih glasov navzven, zatem z zaporednim oženjem in širjenjem dvojic akordov $\mathrm{v}$ diskantu $\mathrm{v}$ triglasju in prehodom do enoglasja; ali npr. $\mathrm{v}$ kromatičnem postopku ob nekončanem sklepu XVIII skladbe (t. 15-17) do unisona, v XIX (t. 1, 2, 3), XX (t. 1-3, 3-4 itd.), XXI (t. 18-19 )in XXII, ki prinaša intervalno širjenje le ene melodije $\mathrm{v}$ postopih navzgor in navzdol (npr. t. 1-4). 
Iz primera vidimo, da se oba glasova simetrično pomikata vsak $\mathrm{k}$ sebi, nato se širita navzven, za tem pa se tako dvoglasje $\mathrm{v}$ diskantu kakor $\mathrm{v}$ basu razveže $\mathrm{v}$ vmesni ton med sozvočno terco in sekundo, obenem ko se diskant in bas kot celota pomakneta še navznoter.

Druge oblike konstruiranja melodije, še tudi v smislu kontrapunktičnih spretnosti, npr. tvorba pozitiva in negativa, tj. zaporedja osnovnega in rakovega postopa, na katero je prvič opozoril skladatelj ob »Črnih maskah" ${ }^{6}$ niso v klavirskih skladbah vidneje upoštevane, ${ }^{7}$ razmeroma redki pa so primeri ritmičnega širjenja in oženja, zlasti avgmentiranja melodičnega gradiva. ${ }^{8}$ Pač pa srečamo pogosteje, še kot posledico vpliva študija kontrapunkta, gradnjo s pomočjo imitacij in sekvenc; zato ni vezana zgolj na uporabo v zadnjem kompozicijskem obdobju, ${ }^{9}$ dokazuje pa, da se skladatelj v klavirskem opusu ni izogibal ponavljanju melodičnega gradiva in ni težil $\mathrm{k}$ doslednejši atematičnosti.

${ }^{6}$ Prim. Vurnik S., Slovenska glasbena produkcija v letu 1926, Dom in svet XL/1927, 127-128 in Klemenčič I., Marij Kogoj - Črne maske (diplomska naloga), 103. Primeri te vrste so sicer v operi redki, vendar so za leto 1926, v luči poznejšega ustvarjanja - kot predhodniki novega pojmovanja melodične gradnje - že značilni.

7 Nakazano obliko pozitiva in negativa prim. $v$ sedmi skladbi "Malenkosti«, na zadnji dve dobi prvega in prvi dve dobi drugega takta. V klavirskih miniaturah najdemo tudi nekaj nedosledno izpeljanih zgledov zrcalne obrnitve, npr. v trinajsti skladbi, kjer se prvemu dvotaktju priključi drugo s smerjo obrnjenega septimnega postopa navzgor, dalje kratko v štirinajsti (t.17) $\mathrm{z}$ obrnjenim štiritonskim zaporedjem, ali v sedemnajsti, s skoki melodije navzgor (t.15) in zatem $\mathrm{v}$ sicer nekoliko drugačni intervalni razporeditvi navzdol (t. 16).

8 Gl. XIV, t. 8-10. Dvotaktna glasbena fraza je tu v altu po začetku povečana (v taktih 9-10) za en takt $\mathrm{s}$ tem, da je njen zaključek (četrtinka s piko, osminka in četrtinka), postavljen sprva za cel ton više kot polovinka, podaljšana za četrtinko ter četrtinka, ki ji sledi po trajanju nespremenjena četrtinka. V peti skladbi, t. 7-10, uporabi Kogoj diminuiran motiv iz začetka kompozicije. Zanimivo je, da se pri obdelavi motivike poslužuje avgmentacije muzikalno izrazito že zgodaj, npr. v "Allegrettu", kjer je prvi takt začetne dvotaktne glasbene fraze, pred koncem (t. 119-120) na subdominanti povečan na običajno dvojno dolžino, ali $v$ "Piano« III, t. 68-69 - po motivu v t. 1 itd. - na dvojno in na zadnjo dobo, na četverno trajanje.

${ }^{9}$ Zlasti imitacij se skladatelj poslužuje razmeroma pogosto, bodisi da že motiviko postavi v okvire imitacijskega odgovarjanja med glasovi (»Malenkost« VIII), ali kadar priložnostno obravnava tako motiv, pa tudi glasbeni domislek ( $\mathrm{V}$, t. $6-7$, punktirani domislek, t. 7-10 motiv v diminuciji, XII, t. 8-9 imitacije med altom in sopranom). Poleg fug zasledimo podobne primere že zgodaj ("Piano" II, t. 128-129, "Piano" III, t. 68-69, $\mathrm{z}$ avgmentiranim motivom, "Piano" V, t. 5 in 14-17, "Piano" VI, t. 29-30). - Sekvenčna gradnja je spočetka bolj v rabi, poleg fug npr. v »Allegrettu" (t. 8-10, 74-75 in 76-77, t. 84-85 in 86-87 ter 108-109 in 109-110), "Andante poco più mosso« (t. 73-78), pa še pozneje v »Andatino sostenuto" (t. $25-26$ in $43-45$, motiv v basu), medtem ko postane v "Malenkostih" na splošno manj izrazita in omejena na redkejše zglede (gl. XVIII, t. 10-11). Ob koncu enajste skladbe (»Prošnja») je petkratno sekvenciranje figure iz štirih osmink navzgor v smislu prošnje še posebej vsebinsko utemeljeno. 
Ob tem velja opozoriti - kot dokazujeta že obe oblikovalni načeli - da Kogojevi strogo konstruktivistični in racionalistični postopki iz poslednjega obdobja ne izvzemajo možnosti emotivnega glasbenega podajanja. Kljub preoblikovanosti v bolj zadržano dikcijo in dejstvu, da gre $\mathrm{v}$ obravnavanem primeru že po naravi za doslednejše linearno pojmovano gradivo, nam dokazujejo še tem bolj eksponirana melodična mesta spevno vsebinsko funkcijo in značaj melodike. Karakterizacija vsebinsko izraznega območja kompozicije sloni poslej še vedno ali celo še $\mathrm{v}$ večji meri na tem kompozicijskem elementu, da lahko po njem povsem določno sklepamo o skadateljevih intencijah. Govorimo lahko o doseženih primerih plesne motorike,

13. »Malenkosti«, VI, t. 1-2.

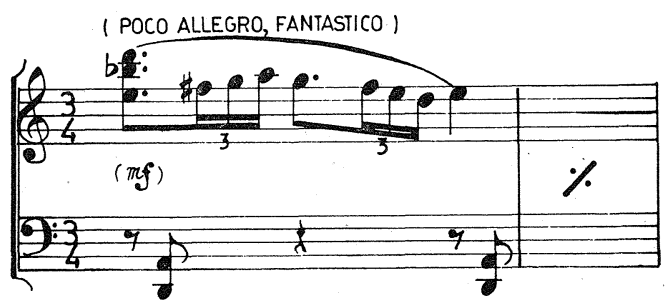

pastoralne idilike,

14. "Malenkosti«, XIII, t. 1-2.

občutenosti v ljudskem duhu,

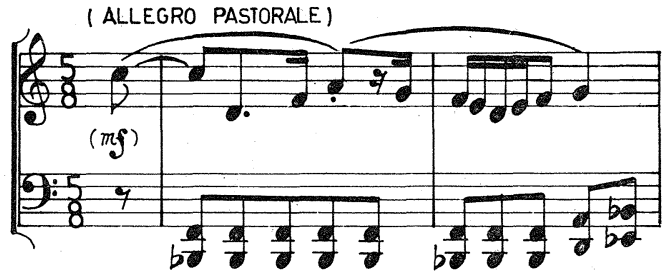

15. »Malenkosti«, XII, t. 1-2.

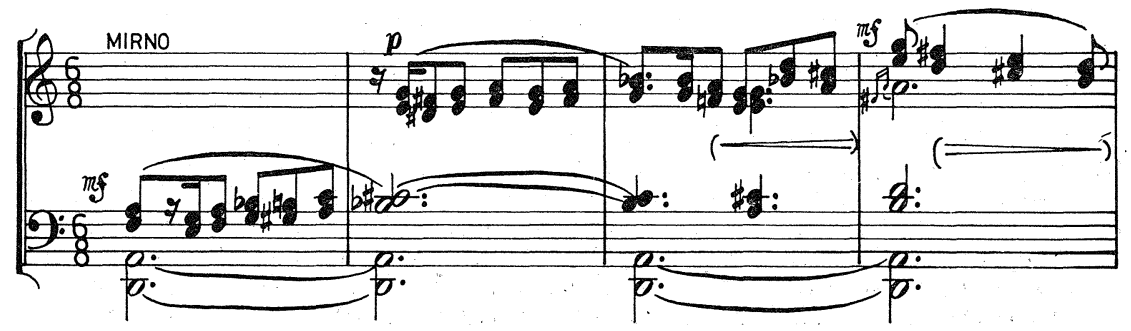

muzikalne poetizacije ${ }^{10}$

${ }^{10}$ Rokopis tega glasbenega primera ima na prvo dobo drugega takta fis $^{2}$ in ne $\mathrm{f}^{2}$, kot posthumna izdaja na (tretjo dobo stoji v obeh tekstih $\mathrm{f}^{1}$ ). 
16. »Malenkosti«, X, t. 1-2.

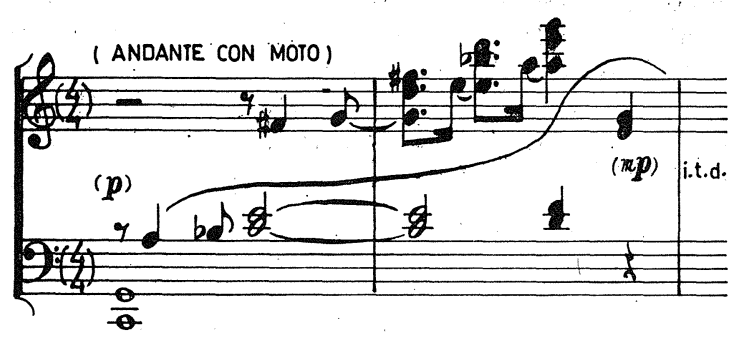

in drugih, sledeč jim do vsebinsko izraznih odtenkov.

$\mathrm{Ne}$ da bi bil pri naši presoji delež spremljave neobhodno potreben, dasi je karakterističen in soodločujoč, dobiva melodika zadnjega obdobja $\mathrm{v}$ precejšnjem delu skladb že $\mathrm{v}$ načinu obravnave nekoliko večji poudarek. Vidnejši je zlasti tam, kjer prihaja do uveljavljanja monodičnega načela deljenja na melodijo in spremljavo. V tem smislu nedvomno najdlje sega zadnja skladba iz »Malenkosti«, saj tvori neprekinjeno ponavljanje njene nedeljive štiritaktne glasbene misli - ob mehanično zasnovani spremljevalni figuri $\mathrm{z}$ nenehnim izmenjavanjem dveh osminskih vrednosti, kljub pozneje dodatno uvedenim glasovom - ogrodje in idejo kompozicije. Čeprav je delo, ki je ostalo nezaključeno, zasnovano $\mathrm{z}$ vzponi in padci in ne $\mathrm{v}$ stalnem crescendu kot podobni Ravelov "Bolero«, tudi navkljub ponavljanju spremljave, skladatelj $\mathrm{z}$ raznimi osvetlitvami melodične fraze uspeva vzpostaviti miselno emotivno kontinuiteto. Peta skladba na primer ni grajena na načelu takšne melodične kontinuitete, saj sestoji že njen enotaktni motiv le iz dveh tonov, toda njegova obravnava in razmerje s spremljavo, celo za Kogoja izjemno $\mathrm{v}$ obliki spremljevalne figure, ki se ponavlja, postavlja motiv v vlogo spremljane melodije. V iskanju takšnih možnosti izražanja naletimo celo na refren kot obliko smiselne izpeljave pesemskega tipa, ki sledi izdatnejši linearni ekspoziciji. Ni pa nemogoča niti uporaba melizmov in izjemoma melodičnih pasaž med dvema tonoma, ki so v primeru »Chopiniane omejeni na značaj posnemane melodike ter segajo v širokem razponu šestih, sedmih, devetih, desetih ali celo triindvajsetih melodičnih tonov, ter prav tako redka raba trilčkov. Sicer so določene, vsebinsko nebistvene figuracije in opisi melodike, ki nastanejo pri uvajanju enotaktnih ali dvotaktnih glasbenih misli s takojšnjo ponovitvijo take enote, znani že prej. ${ }^{11}$

$\mathrm{Za}$ ene in druge pa je značilna tonalna obravnava, ki se $\mathrm{v}$ obdobju do "Črnih mask " zgosti v modulacijsko bolj odmaknjena tonalna območja, medtem ko postane pozneje tonalna zgradba deloma zahtevnejša in manj evidentna, deloma sem in tja preglednejša. Če gre prej po večini za kromatično pojmovanje melodike, se tej pozneje

11 Prim. v »Piano« V, t. 41-42, 48-49 v altu in sopranu $\mathrm{z}$ ritmično gostejšimi postopi, ki zapolnijo kompozicijski stavek, ali t. 65-66 ter minimalno t. $6 \mathrm{~s}$ t. $83-84$. 
v nekaj primerih pridruži tudi bolj diatonično občuteni melos, kot dokazujejo v »Malenkostih« šesta, trinajsta, šestnajsta ali dvaindvajseta skladba. V nasprotni smeri pripomore zlasti tvorba tonskih skupin s težnjo navajanja čim več različnih tonov. Ker se večidel nanaša oz. omejuje na motivično gradivo, je primer začetnega dvotaktja iz četrte skladbe "Malenkosti«, ob ponovitvah $\mathrm{z}$ uporabo desetih različnih tonov (brez dis in $f$ oz. še $z$ enajstim, tonom $f \mathrm{v}$ spremljavi), že ekstremen. Vsekakor skladatelj — najbrž tudi zavestno - do dodekafonije ne pride, saj bi ga serialni način gradnje že formalno preobčutno utesnjeval, nalagal pa bi mu tudi neustrezajoči abstraktni, »nefigurativni« način glasbenega mišljenja.

Pač pa je vsaj omembne vredna občasna raba lestvic mimo dura in mola, ki omogoča med drugim tudi uvajanje navidez tujih tonov v dur-molovski sistem. Primere v tem smislu prinaša "Chopiniana«, npr. $\mathrm{v}$ basu predzadnjega takta znižan a namesto prej nealteriranega, $\mathrm{s}$ frigijskim značajem tonalitete, ali podobno $\mathrm{v}$ sopranu takt pred ponovitvijo začetnega dela. Vendar takšna raba starih cerkvenih lestvic za Kogoja ni zelo značilna in tudi na splošno ne vidna, saj jih bogato alterirani kompozicijski stavek hitro zabriše. Med redke izjeme, kot je denimo osma skladba v »Malenkostih", t. 13-16, ki z delnim opuščanjem tonov dis in fis vzpostavlja in ohranja frigijski značaj melodike, sodi "Chopiniana« tudi zaradi posnemanja Chopinove kompozicijske prakse; zanimivo je nemara, da skladatelj $\mathrm{v}$ želji po originalnosti celo kratko nadomesti značaj starih lestvic s cigansko lestvico, čeprav je stilizirana oblika razveza napolitanskega sekstakorda v c-mol, na izhodiščnih lestvičnih tonih b in c namesto pričakovane zveze b-mol-c-mol, značilna manj po uporabi kot po širini mišljenja.

Poseben, dasi v bistvenem ne nov vidik organizacije melodičnega elementa $\mathrm{v}$ klavirskih kompozicijah nam omogoča intervalna analiza. Skladateljevih prizadevanj nam ne razodeva samo glede obsega izraznih možnosti in pojmovanja, marveč tudi s stališča razvojno izrazne poti, ki jo ima Kogoj za seboj.

Če upoštevamo melodiko - zlasti pa vodilno motiviko - spočetka, ugotavljamo, da jo karakterizira raba majhnih intervalnih postopov. Po najverjetnejši domnevi nas to opozarja na korenine in izhodišče ustvarjalčevega dela $\mathrm{v}$ duševni statičnosti, nerazgibanosti, na način doživljanja, ki se še močno giblje in izčrpava $v$ mejah osebnega sveta. Soočeni smo s specifično potezo Kogojeve mladostne duševnosti, pristopom, ki se na podoben način lahko kaže na začetku te ali one ustvarjalne poti ter določa izrazne značilnosti ne glede na snovno vsebinski okvir skladbe. Zato ni naključno, da obvladuje prav prvenca »Elegijo«, dosledno pa njeno motiviko, interval sekunde (prim. tudi gl. pr. 4), ki ga na začetku »Piana» potrjujejo še »Allegretto in njegova, le s celimi toni in poltoni izpeljana glasbena misel, ali »Andantino cantabile«, kljub postopom terce, čiste kvarte in kvinte, ter podobno »Andante poco più mosso«. Poleg drugih, deloma navedenih razlogov, bi tudi ti potrjevali domnevo, da izvira prva 
polovica ali da sta še posebej prvi dve iz »Piana«, vsaj delno, tj. po prvotni zamisli, iz Gorice. Že teme fug prinašajo namreč večjo razgibanost, ki narašča od f-molove in g-molove do izdatneje razgibane G-durove, kjer se vidno uveljavi poleg drugih melodični interval sekste. Docela logično sodi sem, poleg upoštevanja sekundnih postopov, s postopi terce, čiste kvarte in sekste, tudi "Prélude" in kot plod podobnega izraznega pojmovanja, prav tako $\mathrm{z}$ doseženo seksto, "Più grave« (prim. tudi gl. pr. 1). Ti zgledi torej ne povsem naključno dokazujejo, da se skladatelj pri podajanju vsebine po prvih korakih čedalje bolj osvobaja zadržanosti, zaprtosti v svoj lastni krog in da si $\mathrm{z}$ razvojem osebnosti pridobiva širše razglede ter se obrača $\mathbf{k}$ naravnejši, v osebnostnem smislu sproščenejši in umetniško zrelejši govorici. V prvem ljubljanskem obdobju se ta še dograjuje in ustaljuje, kot sklepamo po intervalni zgradbi »Dolce e tranquillo«, poleg sekundnih in terčnih postopov $\mathrm{z}$ uvajanjem zmanjšane kvinte, ali "Andantino sostenuto", kjer se kromatičnemu značaju uvodnih malih sekund pridruži $\mathrm{v}$ poznejšem melodičnem gradivu, poleg kvarte, kvinte in sekste, še skok oktave. Spevnost in mehkobo sekste prav tako značilno upošteva zadnja skladba iz "Piana«, sem in tja pa se poslužuje skladatelj že tudi bolj razgibane, vendar ne kot ostre, izstopajoče disonance pojmovane septime. ${ }^{12}$ če upoštevamo v tem kontekstu - glede na čas nastanka, še »Skico«, jo moramo zaradi zgodnejšega datuma šteti vsekakor med izjemne dosežke. Domnevno lahko sklepamo tudi o zgledovanju pri Schönbergu ali o njegovem neposrednem vplivu, kar bi moglo razlagati sodobnejše pojmovanje sekunde in kvarte, $\mathrm{z}$ njima pa intervalov zmanjšane kvinte in zvečane kvarte

17. »Skica«, t. 5.

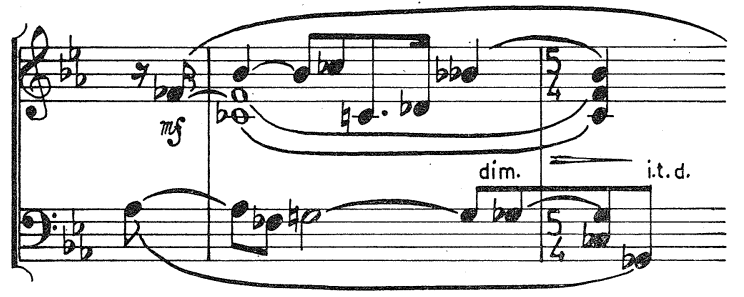

ter poleg septime tudi upoštevanje zmanjšane oktave (prim. prav tam). Tako predstavlja "Skica» po intervalnem dometu melodike, v kateri so možnosti v oktavi izčrpane, doslej višek ekspresivnega oblikovanja, kljub dejstvu, da prinaša njen srednji del in sklep melodični tip, ki je, še tudi s tradicionalnejše pojmovanimi sekundnimi zaporedji, bližji ali vsaj bliže zadnjima dvema skladbama iz »Piana«.

${ }_{12}$ Zato tudi glede pogostejše rabe ti intervali še niso povsem značilni, kot dokazujeta npr. takta 6 ali 17, ali v peti skladbi »Piana« še izrazitejša primera v t. 40.

$6^{*}$ 
Nova razmerja, ki jih prinaša zadnje ustvarjalno obdobje, so značilna po novi radikalizaciji, $s$ težnjo po nadaljnjem melodičnem razgibavanju izraza. Ta opredelitev je sicer paradoksna zaradi bolj statičnega izraza, vendar značilna za slogovno izrazno nadaljevanje in razvijanje Kogojevega znanega izhodišča: glasba zadrži izraznostno funkcijo in $\mathrm{v}$ tem smislu melodično še celo marsikaj nadoknadi, medtem ko se že obrača $\mathrm{k}$ novim, objektivnejšim izrazno slogovnim možnostim in $\mathrm{s}$ tem $\mathrm{k}$ določenemu modificiranju izraza. Zato prihaja zdaj ali šele zdaj do vidnejšega uvajanja značilnih ekspresivnih skokov prek oktave, ki jih je bil uveljavil dunajski ekspresionizem in si jih je v tem obdobju na svoj način prisvojil Kogoj. Tako v sicer zmernejši zasnovi "Chopiniane" polimelodično ni nenavaden postop zmanjšane duodecime, $\mathrm{v}$ posamičnem glasu pa tudi decime in undecime, ali v spremljavi celo tercdecime (gl. t. 1-2). Te izpostavljenosti bistveno ne presežejo pozneje niti »Malenkosti«, čeprav so $\mathrm{v}$ njih uvedene novosti in stare pridobitve postavljene $\mathrm{v}$ novo luč, oz. oboje stopnjevane še določneje v drugi smeri - poudarjanja disonantnosti intervalov. Zlasti odločilno mesto zavzame tu interval septime, ki se kot temeljno gradivo pojavlja v raznih izraznih funkcijah (prim. gl. pr. 12). ${ }^{13} \mathrm{~S}$ pomočjo njega si ustvari Kogoj celo izvirno stalno poetično figuro (prim. gl. pr. 16), značilno oblikovano $\mathrm{z}$ zadržanim spodnjim tonom ob običajnem septimnem skoku in še spremljano terco. ${ }^{14}$ Težnja $\mathrm{k}$ melodični razgibanosti se izraža nadạlje v zavestni uporabi že znanih večjih intervalnih skokov vse do tercdecime in celo dveh oktav, ${ }^{15}$ Kogoj pa se začne posluževati še krajših melodičnih postopov s skokovito, po obsegu znatno razširjeno melodično linijo, ki zajema v smislu nepasažnih, dinamičnih vstavkov oz. dinamizmov Schönbergovega tipa razpon do štirih oktav. ${ }^{16}$ Zanimivo: kljub temu, da zadrži še tudi manjše intervale, doseže skladatelj tako melodično ustrezna sredstva za ekspresionistično izražanje -

${ }^{13}$ Gl. med drugim še XIII, t. 3, I, t. 13, II, t. 15-16, VI, t. 15 itd.

${ }_{14}$ Najtemeljiteje je ta Kogojeva figura obdelana $\mathrm{v}$ deseti skladbi »Malenkosti«, ki je po rokopisu uvrščena kot sedma; se pravi, da je skladatelj prišel že prej do nje, da jo je tu v večji meri izčrpal, a se je pozneje še vračal $\mathrm{k}$ nji. Navajo jo npr. že v drugi skladbi, t.21-22, deveti skladbi (v rokopisu peta), t.19, pa tudi v peti (v rokopisu deveta), t. 9 in $12-13$, in pozneje $v$ štirinajsti, t. $5-6$, ali sedemnajsti, t. $4-5$ in 8 itd. Zanimivo je tudi, da zasledimo podobne, sicer $\mathrm{v}$ tem smislu neznačilne poskuse že v predhodnem obdobju (»Piano« III, t. 41, 51 itd.).

${ }^{15}$ Kot zgled gl. interval zmanjšane oktave v I, t. 13, ali disonantne male none v I, t. 8 in XV, t. 1 , velike none v I, t. 14 in II, t. $2-3$, undecime v II, t. 8, tercdecime v XI, t. 3 v basovski melodični liniji ter razpona dveh oktav v II, t. 4.

${ }^{16} \mathrm{~V}$ tej zvezi prim. Schönbergovo monodramo "Erwartung«, ali začetek komorne simfonije. V "Malenkostih" gl. zlasti drugo skladbo, ki to načelo uvaja že na začetku zbirke (posebej še t. $5 \mathrm{v}$ basu, t. 14 itd.). $\mathrm{Ne}$ povsem identičen primer razpona $v$ tercdecimi prinaša četrta, t. 3-4, izrazitega pa deveta, t. 5 , v obsegu čez tri oktave. 
18. »Malenkosti«, II, t. 1.

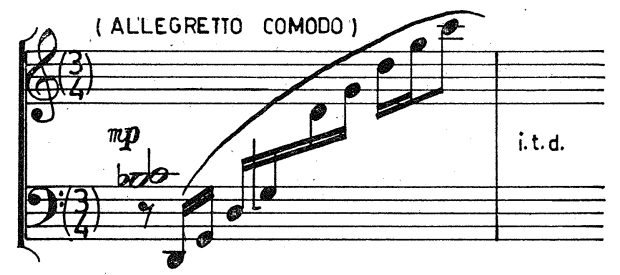

izvzemši »Skico« - šele v fazi, ko se od nje delno že odklanja. Podobno kot tu srečamo takšen odnos tudi $\mathrm{v}$ predhodnem obdobju, kjer Kogojevo usmerjenost k ekspresiji spremlja še upoštevanje novoromantičnih kompozicijskih sredstev. Skupno vsem, kot bi bilo dopustno sklepati $\mathrm{v}$ zasledovanju tega razvoja tudi $\mathrm{v}$ bodoče, če ga ne bi prekinila bolezen, je torej temeljno pojmovanje glasbe kot izrazne umetnosti, zvestoba samemu sebi, čemur se - skladno z razvojnimi dosežki v svetu, podrejajo sredstva in slog.

\section{SUMMARY}

In his piano compositions the composer Marij Kogoj continues the tradition of homophonic musical thinking. However, this was not sufficient, so that with the introduction of free polyphonic parts this homophonic fundament received a more minute, psychologically determined content. Kogoj's counterpoint, in fact a romantic heritage, originated as a polymelodic unity of the homophonic and polyphonic principle; at first with the accent on homophony with the ramification of harmonic parts (during his studies in Vienna under Schreker and Schönberg) and with the polyphonic hypertrophy of voices, typical of the neo-romantic idiom, which clarified after the first World War and then later (in the final period up to 1932) with the introduction of a more linear foundation of the texture.

In keeping with the tonal or still tonal harmonic design of the composition with the non-abstract, still neo-romantic way of musical thinking are the melodics - melodious and accentuated in the upper part. At the same time their development soon becomes complicated: dispersed motivic embryos as well as a mass of musical ideas appear to be the more progressive musical elements. With such a way of musical thinking, instead of using a rounded-off melody or theme, the composer most appropriately follows and adapts himself to quickly changing psychic happenings. On one hand his model extends to the edge of athematic style, although he cannot completely by-pass tradition (according to Scriabin's and Chopin's melodic models), whereas in his last phase he makes sensitive use of some contrapuntal constructional elements. In this period of partial rationalisation he surprisingly introduces constructivistic elements into his temporarily subjectivistic style especially in the form of the countermovement of two or more melodies.

His personal stylistic development becomes especially evident from an analysis of intervals. In his earlier period his starting point was static 
romantic pessimism almost exclusively in intervals of seconds, which gradually grow beyond neo-romantic expression. With the emphasis on the fourth, seventh and second - in a new role - Kogoj reaches the summit in his mature period with his concise "Sketch" with which he explicitly, yet individually, joins expressionism. In his final period dissonant jumps beyond the octave bring him near to Schönberg's atonality and expressionism, although he simultaneously retreats from this; instead of dodecaphony he turns to Neue Sachlichkeit (with constructivistic elements and with less frequent neo-classical diatonics), or more precisely to its initial idealistic phase as an extension of expressionism. Thus he reaches melodically adequate means of expressionistic writing - except his "Sketch" - only in the phase when he is already partly deviating from it. (We find a similar situation in the previous period, in which Kogoj's orientation towards expression is accompanied by neo-romantic compositional elements.) 